\title{
Errors in Surgical Site Identification during Cutaneous Surgery for Skin Cancer: Review and Recommendations
}

\author{
Sharad P. Paul ${ }^{1,2,3}$ \\ ${ }^{1}$ University of Queensland, Auckland, New Zealand \\ ${ }^{2}$ University of Auckland, Auckland, New Zealand \\ ${ }^{3}$ Skin Surgery Clinic, Auckland, New Zealand \\ Email: doctor@skinsurgeryclinic.co.nz
}

Received 25 June 2015; accepted 19 July 2015; published 22 July 2015

Copyright (C) 2015 by author and Scientific Research Publishing Inc.

This work is licensed under the Creative Commons Attribution International License (CC BY).

http://creativecommons.org/licenses/by/4.0/

(c) (i) Open Access

\begin{abstract}
Surgical error due to incorrect identification of the surgical site has been known to occur right from the beginning of surgical practice through the ages. However, increasing awareness, preventative efforts and risks of litigation have not eliminated this problem. Cutaneous surgery for skin cancer makes up a large proportion of procedures performed each year and it is often difficult to correctly identify biopsy sites, especially as this is not easy in sun-damaged skin. In this review article, we review the incidence of wrong-site surgery, measures taken by professional bodies, and the use of photography and newer technologies in an attempt to eliminate this distressing event in the field of plastic and dermatologic surgery. The purpose of this review is to highlight the incidence of such surgical site identification errors, evaluate the risk factors, and educate the surgeon about measures that can be undertaken to avoid being faced with such a situation.
\end{abstract}

\section{Keywords}

Skin Cancer, Medical Error, Patient Safety, Dermatology, Wrong Site Surgery, Melanoma

\section{Introduction}

In the United States, more than 1.3 million new non-melanoma skin cancers (NMSC) occur each year, causing significant morbidity and being responsible for high healthcare costs [1]. In actinic-damaged skin of elderly patients, due to the diffuse photo-damage and prior surgical procedures, biopsy scars are often barely distinguishable from background skin. Therefore in plastic and dermatologic surgery, skin cancers present a high risk for pa- 
tients with melanoma presenting for wider excisions, or patients with non-melanoma skin cancers presenting for formal excision after an initial biopsy. In a survey of referrals for Moh's micrographic surgery, without photography, patients incorrectly identified $16.6 \%$ to $29 \%$ of biopsy sites [2] [3]. However variances in the precision of individual record-keeping by physicians and the difficulty with complete implementation of emerging electronic health records limit pictorial documentation [4]. Further, often a biopsy is performed by a different physician who then refers the patient to another for more complex surgery. A survey showed that wrong-site surgery was among the most common reasons for a lawsuit against Moh's surgeons [5]. With increased awareness and preventive efforts, it is unsettling that wrong site surgery remains a persistent problem, with some data suggesting that the incidence may even be rising [6]-[8]. While in dermatologic surgery or plastic surgery, there may not be severe physical harm, the absence of measured permanent injury does not correlate with the patient's perception of harm, anger or fractured trust [9]. Stiff penalties have been established by institutions such as the Board of Medicine in Florida, demonstrating the public's not unreasonable intolerance to wrong-site surgery [10].

\section{Discussion}

In dermatologic or plastic surgery, there is often a need to perform a wider excision following an initial confirmatory biopsy for non-melanoma skin cancers. And with respect to melanoma, the situation is unique-almost all patients with melanoma end up with two operations-the first an initial excision, followed by a wide local excision. Standard treatment for malignant melanoma involves a wide excision around the original tumour site. The recommendation of $5 \mathrm{~cm}$ margins for wide excision was originally made by Sampson Handley in 1907 [11]. Since then, while the margins needed for a wide excision have been whittled down, most experts agree that mortality after local recurrence is high and that a wide excision offers the best chance of a cure [12]. Expanding on this "field effect" theory, Cochran [13] noted increased numbers of melanocytes in skin surrounding many melanomas, and Wong [14] noted morphologically abnormal melanocytes up to $5 \mathrm{~cm}$ away from the original tumour. Olsen's contamination theory suggested that melanocytes around the tumour were "activated" by the melanoma cells and also advocated wider excision [15]. Others felt that the main benefit of wide excision was avoidance of traumatizing the primary lesion, thereby avoiding embolization or cell implantation [16]. As melanoma excision margins came down from the original $5 \mathrm{~cm}$, Breslow and Macht [17] found no local recurrences inlesions $<0.76 \mathrm{~mm}$ deep. The incidence of cutaneous melanoma has increased over the past 25 years, and a significant number (approximately 20\%) of these tumors are found on the head and neck [18]. The recommended gross surgical margins are $1 \mathrm{~cm}$ for T1 tumors ( $\leq 1 \mathrm{~mm}$ in thickness) [19] and $2 \mathrm{~cm}$ for T2 (1.01 - 2 $\mathrm{mm})$, T3 $(2-4 \mathrm{~mm})$, and T4 $(>4 \mathrm{~mm})$ tumors [20]. Some surgeons have advocated delaying wider excision, especially when skin grafts are used due to concern for surveillance of subsequent local recurrence [21]. While margins for wide excision have been standardised, several prospective, randomised controlled trials have compared narrow margins with wide margins in patients with melanomas of more than $1 \mathrm{~mm}$ Breslow thickness. Local recurrence rates were very low, and overall survival did not differ significantly [22]-[26]. Other reviews and meta-analyses to do with wide excision margins for primary melanoma sites also failed to show any statistically significant difference in overall survival. The authors of a Cochrane review concluded that "current randomised trial evidence is insufficient to address optimal excision margins for primary cutaneous melanoma" [27]-[29]. Nevertheless, given wide excision is the norm after the initial excision after melanoma, it is important to ensure that the correct site is excised, as it is often difficult to identify a well-healed primary site.

Wrong site surgery is probably as old as surgery itself. Traquair, an ophthalmologic surgeon, in 1947 described the "important and very pertinent disaster of wrong site surgery where enucleations of the wrong eye have been performed" [30]. Wrong site surgery can be simply defined as "the performance of an operation or surgical procedure on the wrong part of the body" [31]. There is a viewpoint that providing an operative briefing, complete with a discussion of operative goals and potential complications, will further reduce wrong-site frequency [32].

Backster et al found that a "preparatory pause" to discuss a 5-point perioperative risk avoidance strategy raised compliance from $50 \%$ to $90 \%$ over 167 procedures [33]. In a review of data from the Pennsylvania Patient Safety Reporting System, Clarke et al found that $4.7 \%$ of reporting facilities had more than 1 wrong-site surgery in a 12 -month span, and 427 cases of wrong-site surgery occurred over a 30-month period. Interestingly, these events occurred despite successful completion of a preoperative time-out [34]. 


\section{Regulatory Body Reviews}

The National Quality Forum and Centers for Medicare \& Medicaid Services consider wrong-site surgery to be a "never event" [35]. The Joint Commission's Sentinel Event database reported an incidence as high as 40 wrongsite procedures a week in the USA [36]. In one review, the incidence was estimated to be 0.09 to 4.5 per 10,000 operations [37]. When we look at all paid claims in the National Practitioner Data Bank and literature estimates of surgical adverse events, it is estimated that 2058 wrong site, wrong procedure, or wrong patient claims occur yearly in the United States [38]. Over the past two decades, surgical practice has developed more openness with regard to reporting adverse events, and indeed aside from medico-legal awareness, reporting these adverse events is now mandatory in several states in America [39]. An opinion in the Institute of Medicine: Committee on Quality of Healthcare's 1999 report, "To Err Is Human", reiterated the principle that such errors, while human errors should be considered a "system malfunction" [40] [41]. As Leape noted, "Errors are not diseases: they are symptoms of diseases" [42]. In the nineties, several specialty-specific surgical injury-prevention measures were promoted with slogans like "Sign Your Site", and "Sign, Mark, and X-ray" [43].

Wrong site surgery in the United States is the most commonly reported sentinel event [44] [45]. In the United Kingdom, wrong-site surgery is estimated to occur in about 1 in 1000 procedures [46]. The National Patient Safety Agency, the body that keeps a record of all safety incidents from surgical specialties in England and Wales, reported as many as 155,000 incidents to its National Reporting and Learning Service in one year, from 1 January 2009 to 31 December 2009 [47]. In the same year, García-Germán Vázquez's team in Madrid noted a significant correlation between the incidence of wrong-site surgery and the annual number of procedures performed, and a non-significant relationship with the age and length of service. Incidence was one case in every 27,686 procedures [48]. A failure of teamwork was noted in a study by the AAOS (American Academy of Orthopaedic Surgeons) working group, in $46 \%$ of cases the blame corresponds only to the surgeon, but in $41 \%$ of cases it is the surgical team that has draped or marked the wrong side [49]. The AAOS also commented on the legal implications-as Levy wrote in an AAOS newsletter, it is virtually impossible to succeed in getting a surgeon to be declared not liable in cases of wrong site surgery [50]. And even as the AAOS made stringent efforts to raise awareness, in 2002, while $78 \%$ of AAOS members knew about the program, only $46 \%$ used it in daily practice [51]. Ultimately it all comes down to the operating surgeon. As Ausman noted, not only are surgeons responsible for the preoperative surgical planning, but also they must inform/educate the OR (operating room) staff regarding operative requirements of procedures including location of the bodily site [52].

The Joint Commission on Accreditation of Healthcare Organization's Sentinel Events Database from 1995 through 2005 ranked wrong-site surgery as the second most common reported event [53].

The Joint Commission defines wrong-site surgery as any surgery performed on the wrong site or patient or performance of the wrong procedure on a patient [54]. This can often happen in dermatologic or plastic surgery, especially as scars can be difficult to identify in severely actinic damaged skin, or the patient perception of what was a suspicious lesion originally may vary from the doctor's diagnosis, or the patient is referred to a second practitioner for a wider excision after initial biopsy. A recent survey of 300 dermatologist Moh's surgeons in the USA revealed that 6 of 42 (14\%) malpractice cases were a result of wrong-site surgery [55].

The incidence of error in identifying the correct site during cutaneous surgery specifically may not be known, but a study conducted at the Veterans Health Administration suggests that when compared with other specialties, at least $1.4 \%$ of surgical adverse events were caused by medical practitioners performing cutaneous surgery [56]. Melanoma, especially the wider excision procedure after initial melanoma excision, presents a potentially higher risk given the patient is often referred by a GP to a surgeon or specialist for the second procedure. As the surgeon often relies on the referring doctor's anatomic description, and the patients' own ability to identify the site, it is important that steps are taken to minimize risk.

To reduce further the chances of the wrong site being removed, referring clinicians (or indeed any clinician) should be expected to use as accurate an anatomical description as possible. For example, in the case highlighted by Al-Rawi and Varma, two lesions in close proximity may lie in different cosmetic subunits of the nose, and on the face such aesthetic subunits may serve as guides to noting the exact location of the lesions [57]. On the trunk, it may be advisable to not only include photographs with the referral, but also to measure the distance to a particular anatomical landmark for e.g. ". $.8 \mathrm{~cm}$ to the right of the spine in the 4th intercostal space".

It has become commonplace for patients to have smartphones that have a high-resolution camera as part of their function, and this is something that may be used for the benefit of the patient in preventing wrong site sur- 
gery. Patients are often agreeable to taking a photograph of the biopsy site with their own phone, to bring with them at their subsequent outpatient clinic or theatre appointment with another doctor [58]. To reduce the risk of wrong-site surgery and also litigation, Ibrahim suggests invoking a standardized procedure for all patients: hand the patient a mirror and have him or her point to the biopsy site, delineate the area with a surgical marking pen, and reconfirm the site with the patient [59]. While this sounds a simple and effective technique, the problem is many patients cannot actually identify the correct site of pathology, either due to visual problems, understanding of the morphology of suspicious lesions, or confusion. A recent study of dermatology patients showed that nearly a third (31.4\%) of subjects were unable to accurately identify their skin biopsy site [60]. Indeed, when we look at the literature pertaining to wrong-site surgery in orthopedics, $37 \%$ of patients actually declined to mark their surgical site, and $4 \%$ of patients marked it incorrectly; patients expect the medical system to "take care of everything". Most patients do not feel the need to take personal responsibility for their care especially with resect to marking sites of surgery [61]. Even though most cutaneous surgeons use photography for clinical purposes, a recent survey amongst dermatological surgeons-the members of the American College of Moh's Surgery found that only $47 \%$ of physicians used photography to confirm biopsy sites [62].

The other issue with non-melanoma skin cancer surgery such as basal cell cancer is that when there is delay between the biopsy and a definitive procedure, the scar is well healed and may not be visible. The other confounding variable is that, as a study demonstrated, $66 \%$ of clinically healed BCC biopsy sites had histopathology evidence of residual tumor [63]. Rossy and colleagues noted that just under a tenth of patients could not identify their surgical sites accurately [64], and McGinness and colleagues found that patients and physicians were incorrect in identifying biopsy sites $4.4 \%$ of the time [65]. There is a viewpoint that while most surgeons preferred using photographs to identify the previous biopsy site, but there may be variation in photographic techniques that could make this method less optimal than perhaps using dermoscopy as an aid [66] [67]. The authors noted that when it comes to dermoscopy of biopsy-site scars, a white-pink homogenous patch with underlying vessels is seen; "chrysalis structures" are not commonly seen in early scar. Clear demarcation from surrounding skin is noted by a hypo-pigmented border separating scar patch from surrounding skin (often actinically damaged) skin. [67] Tattoos or the introduction of dermal pigmentation has been widely used in various oncological subspecialties to mark the location of colon cancer removal, facial prosthesis placement, or radiotherapy portals [68]. However, these tattoos are permanent and may be mistaken for pigmented lesions and therefore some have suggested using fluorescent tattoo ink that is only visible under a limited spectrum of light, such as a Wood's Lamp [69]. There are some commercially available tattoo-fluorescent dyes, where the fluorescent dye is captured within small beads of polymethylmethacrylate (PMMA), which prevents degradation and cutaneous sensitivity to the UV-fluorescent dye [70]. These tattoo dyes are however not FDA-regulated, and formal safety testing is not available, but communication with the FDA indicates that there is no report of an adverse reaction to the "Crazy Chameleon" UV-fluorescent tattoo that was trialed in a report [71]. However, the Food and Drug Administration (FDA) has now approved PMMA that was described above, as a component of an orthopedic prosthesis and for dermal injection fillers [72].

Wrong-site surgery in dermatology or plastic surgery, like many other specialties like otolaryngology, results in temporary injuries to the majority, with few reported cases of permanent disability or death [73] [74]. The Universal Protocol, which was mandated by the Joint Commission in 2004, appears insufficient in eliminating wrong-site surgery [75]. One improvement was an anatomic marking form, which was an innovation designed to improve the efficiency of the Universal Protocol, and has proven effective in at least one institution [76]. The World Health Organization (WHO) checklist and the Surgical Patient Safety System have both been shown to reduce mortality and complications in multicenter randomized, controlled trials-however, no prospective trials have directly examined the specific effect of surgical checklists with respect to wrong site surgical mishaps [77] [78].

However, there is one retrospective study that analyzed a large patient safety database and determined that the WHO checklist could have prevented $83 \%$ of wrong site surgery incidents with actual harms and $15 \%$ of the near misses [79]. It could have a simple explanation-the checklist requires everyone to be introduced at the start of "time-out," creating an activation phenomenon that raises people's sense of openness and engenders a willingness to speak up regarding any concerns [80]. Studies have shown that shown that patients were usually the most reliable informants and even when documentation about the surgical site is often inconsistent, patients are often more accurate in their assessment of site than physicians [81]. However, when studies used patients to mark the surgical sites, they found this to be unreliable, with $32 \%$ to $37 \%$ non-compliancy rates [82] [83]. It 
must be stated that anatomic marking forms that require direct participation by both the surgeon and patient, with both signing and dating the form to maximize accuracy, have been successfully used in one institution with only one implementation error in 112,500 patients over 4.5 years; however, that error was indeed a wrong-site skin lesion excision [84].

It is of note that a Cochrane review performed in 2012 on all interventions for reducing wrong-site surgery rejected 17 of the 18 potentially relevant articles because they lacked data on incidence, leaving only one study for analysis [85]. This study showed that an educational program targeted at residents made a significant impact on wrong-site dental extractions in an outpatient university dental clinic in Taiwan-even if it was limited by the fact that is was confined to a single institution performing only dental surgery [86]. It may well be that that "wrong-site surgical procedures are statistically too rare to serve as quantitative outcome measures of change" [87]. Giles et al. reported that most surgeons have experienced wrong-site surgery with no specific risk factors or causes identified prior to the event [88]. Nevertheless, the elimination of wrong site surgery remains an ongoing challenge and continues to call for innovative use of newer technology in documentation [89]. And finally, whenever a surgeon is faced with the unfortunate occurrence of a wrong-site procedure, it is important to abide by the principle of always acting in the patient's best interest [90].

\section{Conclusions}

\section{Key Points and Recommendations}

- Wrong-site surgery is the second most common reported adverse event;

- At least $1.4 \%$ of surgical adverse events are caused by doctors performing cutaneous surgery, and wider excision following initial biopsy of a skin lesion presents a higher risk;

- Almost a third of patients are unable to identify their original excision site correctly;

- Almost half of the doctors performing cutaneous surgery do not photograph initial biopsy sites;

- Use of photography (including patients' smartphones), accurate anatomic description in clinical notes (in relation to aesthetic sub-units and anatomic landmarks) and marking prior to surgery (with confirmation by the patient using a hand-held mirror) can minimize the risk of wrong-site surgery;

- Dermoscopy may be useful and some authors are experimenting with fluorescent-tattoo inks as a means of identifying biopsy sites.

Cutaneous surgery in general poses a higher risk for wrong-site surgery, especially when it comes to wider excisions following skin cancer. Given patients are often unsure, it makes it doubly important for doctors to ensure anatomic sites are accurately described in the clinical notes (with references to subunits and anatomical landmarks); photography is performed when referring a patient for wider excision, and the patient shows the site (after surgical marking) of the proposed wider excision site immediately prior to surgery.

Ultimately, wrong-site surgery does not "just happen" to surgeons and systems must be developed to ensure maximum patient safety and minimize (if not eliminate) preventable adverse events in cutaneous surgery.

\section{References}

[1] Rogers, H.W., Weinstock, M.A., Harris, A.R., Hinckley, A.R., et al. (2010) Incidence Estimate of Non-Melanoma Skin Cancer in the United States, 2006. Archives of Dermatology, 146, 283-287. http://dx.doi.org/10.1001/archdermatol.2010.19

[2] McGinness, J.L. and Goldstein, G. (2010) The Value of Preoperative Biopsy-Site Photography for Identifying Cutaneous Lesions. Dermatologic Surgery, 36, 194-197. http://dx.doi.org/10.1111/j.1524-4725.2009.01426.x

[3] Ke, M., Moul, D., Camouse, M., Avram, M., et al. (2010) Where Is It? The Utility of Biopsy-Site Photography. Dermatologic Surgery, 36, 198-202. http://dx.doi.org/10.1111/j.1524-4725.2009.01425.x

[4] Campbell, R.M., Perlis, C.S., Malik, M.K. and Dufresne Jr., R.G. (2007) Characteristics of Mohs Practices in the United States: A Recall Survey of ACMS Surgeons. Dermatologic Surgery, 33, 1413-1418. http://dx.doi.org/10.1097/00042728-200712000-00001

[5] Perlis, C.S., Campbell, R.M., Perlis, R.H., Malik, M., et al. (2006) Incidence of and Risk Factors for Medical Malpractice Lawsuits among Mohs Surgeons. Dermatologic Surgery, 32, 79-83. http://dx.doi.org/10.1097/00042728-200601000-00016

[6] Clarke, J.R., Johnston, J., Blanco, M. and Martindell, D.P. (2008) Wrong-Site Surgery: Can We Prevent It? AdvSurg, 42, 13-31. 
[7] James, M.A., Gray, J., Iii, S., Harrast, J.J., Emery, S.E. and Hurwitz, S. (2012) The Occurrence of Wrong-Site Surgery Self-Reported by Candidates for Certification by the American Board of Orthopaedic Surgery. Journal of Bone and Joint Surgery, 94, e2(1-12).

[8] State of New York Department of Health (2008) The New York Patient Occurrence and Tracking System (NYPORTS). http://www.health.ny.gov/facilities/hospital/nyports/index.htm.

[9] Gallagher, T.H. (2009) A 62-Year-Old Woman with Skin Cancer Who Experienced Wrong-Site Surgery: Review of Medical Error. The Journal of the American Medical Association, 302, 669-677. http://dx.doi.org/10.1001/jama.2009.1011

[10] The Joint Commission (2001) A Follow-Up Review of Wrong Site Surgery. Sentinel Event Alert. http://www.jointcommission.org/assets/1/18/SEA_24.pdf.

[11] Handley, W.S. (1907) The Pathology of Melanotic Growths in Relation to Their Operative Treatment. The Lancet, 1, 927-933, 996-1003.

[12] Stehlin, J.S. and Clark, R.L. (1965) Melanoma of the Extremities. The American Journal of Surgery, 110, 366-383. http://dx.doi.org/10.1016/0002-9610(65)90076-0

[13] Cochran, A.J. (1971) Studies of the Melanocytes of the Epidermis Adjacent to Tumors. Journal of Investigative Dermatology, 57, 38-43. http://dx.doi.org/10.1111/1523-1747.ep12292060

[14] Wong, C.K. (1970) A Study of Melanocytes in the Normal Skin Surrounding Malignant Melanomata. Dermatologica, 141,215-225. http://dx.doi.org/10.1159/000252469

[15] Olsen, G. (1966) The Malignant Melanoma of the Skin: New Theories Based on a Study of 500 Cases. Acta Chirurgica Scandinavica, Supplementum, 365, 1-220.

[16] Elias, E.G., Didolker, M.S., Goel, I.P., et al. (1977) A clinic-Pathologic Study of Prognosis Factors in Cutaneous Malignant Melanoma. Surgery, Gynecology \& Obstetrics, 144, 327-334.

[17] Breslow, A. and Macht, S.D. (1977) Optimal Size of Resection Margin for Thin Cutaneous Melanomas. Surgery, Gynecology \& Obstetrics, 145, 691-692.

[18] Jemal, A., Siegel, R., Xu, J., et al. (2010) Cancer Statistics, 2010. CA: A Cancer Journal for Clinicians, 60, $277-300$. http://dx.doi.org/10.3322/caac.20073

[19] (1993) National Institutes of Health Consensus Development Conference Statement on Diagnosis and Treatment of Early Melanoma, January 27-29, 1992. The American Journal of Dermatopathology, 15, 34-43; Discussion 46-51. http://dx.doi.org/10.1097/00000372-199302000-00006

[20] Balch, C.M., Urist, M.M., Karakousis, C.P., et al. (1993) Efficacy of 2-cm Surgical Margins for Intermediate-Thickness Melanomas (1 to $4 \mathrm{~mm}$ ). Results of a Multi-Institutional Randomized Surgical Trial. Annals of Surgery, 218, 262-267; Discussion 267-269. http://dx.doi.org/10.1097/00000658-199309000-00005

[21] Bumsted, R.M., Panje, W.R. and Ceilley, R.I. (1983) Delayed Skin Grafting in Facial Reconstruction. When to Use and How to Do. Archives of Otolaryngology, 109, 178-184. http://dx.doi.org/10.1001/archotol.1983.00800170044012

[22] Balch, C.M., Soong, S.J., Smith, T., et al. (2001) Long-Term Results of A Prospective Surgical Trial Comparing $2 \mathrm{~cm}$ vs. $4 \mathrm{~cm}$ Excision Margins for 740 Patients with 1 - 4 mm Melanomas. Annals of Surgical Oncology, 8, 101-108. http://dx.doi.org/10.1007/s10434-001-0101-x

[23] Khayat, D., Rixe, O., Martin, G., et al. (2003) Surgical Margins in Cutaneous Melanoma (2 cm versus 5 cm for Lesions Measuring Less than 2.1-mm Thick). Cancer, 97, 1941-1946. http://dx.doi.org/10.1002/cncr.11272

[24] Ringborg, U., Andersson, R., Eldh, J., et al. (1996) Resection Margins of 2 versus $5 \mathrm{~cm}$ for Cutaneous Malignant Melanoma with a Tumor Thickness of 0.8 to $2.0 \mathrm{~mm}$ : Randomized Study by the Swedish Melanoma Study Group. Cancer, 77, 1809-1814. http://dx.doi.org/10.1002/(SICI)1097-0142(19960501)77:9<1809::AID-CNCR8 $>3.0 . C O ; 2-6$

[25] Veronesi, U., Cascinelli, N., Adamus, J., et al. (1988) Thin Stage I Primary Cutaneous Malignant Melanoma. Comparison of Excision with Margins of 1 or $3 \mathrm{~cm}$. The New England Journal of Medicine, 318, 1159-1162. http://dx.doi.org/10.1056/NEJM198805053181804

[26] Thomas, J.M., Newton-Bishop, J., A'Hern, R., et al. (2004) Excision Margins in High-Risk Malignant Melanoma. The New England Journal of Medicine, 350, 757-766. http://dx.doi.org/10.1056/NEJMoa030681

[27] Haigh, P.I., DiFronzo, L.A. and McCready, D.R. (2003) Optimal Excision Margins for Primary Cutaneous Melanoma: A Systematic Review and Meta-Analysis. Canadian Journal of Surgery, 46, 419-426.

[28] Lens, M.B., Nathan, P. and Bataille, V. (2007) Excision Margins for Primary Cutaneous Melanoma: Updated Pooled Analysis of Randomized Controlled Trials. Archives of Surgery, 142, 885-891.

http://dx.doi.org/10.1001/archsurg.142.9.885 
[29] Sladden, M.J., Balch, C., Barzilai, D.A., et al. (2009) Surgical Excision Margins for Primary Cutaneous Melanoma. Cochrane Database of Systematic Reviews, No. 4, Article No. CD004835. http://dx.doi.org/10.1002/14651858.cd004835.pub2

[30] Traquair, H. (1947) Removal of the Wrong Eye. British Journal of Ophthalmology, 31, 8-12.

[31] Gibbs, V.C. (2005) Patient Safety Practices in the Operating Room: Correct-Site Surgery and Nothing Left Behind. The Surgical Clinics of North America, 85, 1307-1319.

[32] Makary, M.A., Mukherjee, A., Sexton, J.B., et al. (2007) Operating Room Briefings and Wrong-Site Surgery. Journal of the American College of Surgeons, 204, 236-243. http://dx.doi.org/10.1016/j.jamcollsurg.2006.10.018

[33] Backster, A., Teo, A., Swift, M., et al. (2007) Transforming the Surgical "Time-Out" into a Comprehensive "Preparatory Pause". Journal of Cardiac Surgery, 22, 410-416. http://dx.doi.org/10.1111/j.1540-8191.2007.00435.x

[34] Clarke, J.R., Johnston, J. and Finley, E.D. (2007) Getting Surgery Right. Annals of Surgery, 246, 395-403. http://dx.doi.org/10.1097/SLA.0b013e3181469987

[35] Ring, D.C., Herndon, J.H. and Meyer, G.S. (2010) Case 34-2010: A 65-Year-Old Woman with an Incorrect Operation on the Left Hand. The New England Journal of Medicine, 363, 1950-1957. http://dx.doi.org/10.1056/NEJMcpc1007085

[36] The Joint Commission Center for Transforming Healthcare. Reducing the Risk of Wrong Site Surgery (accessed 30 May 2015). http://www.centerfortransforminghealthcare.org/UserFiles/file/CTH WSS Storyboard final 2011.pdf.

[37] DeVine, J., Chutkan, N., Norvell, D.C. and Dettori, J.R. (2010) Avoiding Wrong Site Surgery: A Systematic Review. Spine, 35, S28-S36. http://dx.doi.org/10.1097/BRS.0b013e3181d833ac

[38] Mehtsun, W.T., Ibrahim, A.M., Diener-West, M., Pronovost, P.J. and Makary, M.A. (2013) Surgical Never Events in the United States. Surgery, 153, 465-472. http://dx.doi.org/10.1016/j.surg.2012.10.005

[39] Robinson, P. and Muir, L. (2009) Wrong-Site Surgery in Orthopaedics. Journal of Bone and Joint Surgery, 91, 1274-1280. http://dx.doi.org/10.1302/0301-620X.91B10.22644

[40] Eisenberg, J.M. (2000) Continuing Education Meets the Learning Organization: The Challenge of a Systems Approach to Patient Safety. The Journal of Continuing Education in the Health Professions, 20, 197-207. http://dx.doi.org/10.1002/chp.1340200403

[41] Institute of Medicine (2000) Committee on Quality of Healthcare in America. In: Kohn, L.T., Corrigan, J.M. and Donaldson, M.S., Eds., To Err Is Human: Building a Safer Health System, The National Academy Press, Washington DC.

[42] Leape, L.L. (2004) Errors are Not Diseases: They Are Symptoms of Diseases. The Laryngoscope, 114, $1320-1321$. http://dx.doi.org/10.1097/00005537-200408000-00002

[43] Michaels, R.K., Makary, M.A., Dahab, Y., et al. (2007) Achieving the National Quality Forum's "Never Events": Prevention of Wrong Site, Wrong Procedure, and Wrong Patient Operations. Annals of Surgery, 245, 526-532. http://dx.doi.org/10.1097/01.sla.0000251573.52463.d2

[44] The Joint Commission. Sentinel Event Data: Event Type by Year (1995-2011) (accessed 14 July 2012). http://www.jointcommission.org/sentinel_event.aspx.

[45] Agency for Healthcare Research and Quality. Patient Safety Primers: Never Events. Patient Safety Network (accessed 2 March 2012). http://psnet.ahrq.gov/primer.aspx?primerID53

[46] Kwann, M., Studdert, D.M., Zinner, M.J., et al. (2006) Incidence, Patterns, and Prevention of Wrong-Site Surgery. Archives of Surgery, 141, 353-358. http://dx.doi.org/10.1001/archsurg.141.4.353

[47] National Patient Safety Agency. National Reporting and Learning Service (accessed 30 May 2015). www.nrls.npsa.nhs.uk/

[48] García-Germán Vázquez, D., et al. (2009) Wrong Site Surgery. Revista Española de Cirugía Ortopédica y Traumatologia, 53, 332-339. http://dx.doi.org/10.1016/j.recot.2009.01.004

[49] Canale, T.S. (accessed 30 May 2015) OK Plan to End Wrong-Site Surgeries. October 1997 Bulletin, American Academy of Orthopaedic Surgeons. http://www2.aaos.org/bulletin/oct97/wrong.htm

[50] Levy, D.A. (1998) No Defense for Wrong-Site Surgery. AAOS Bulletin, 46, 18. http://www2.aaos.org/bulletin/jun98/legalcol.htm

[51] Wong, D.A. (accessed 30 May 2015) Surgical Site Marking Comes of Age. April 2004 Bulletin, America Academy of Orthopaedic Surgeons. http://www2.aaos.org/bulletin/apr04/feature1.htm

[52] Ausman, J.I. (1999) The Business of Surgery: Business Principles Applied to Preoperative Planning, Operating Room Management, and Surgical Strategy. Surgical Neurology, 51,113-114.

[53] Devine, J., Chutkan, N., Norvell, D.C. and Dettori, J.R. (2010) Avoiding Wrong Site Surgery. Spine, 35, S28-S36. http://dx.doi.org/10.1097/BRS.0b013e3181d833ac 
[54] Joint Commission. A follow-Up Review of Wrong Site Surgery (accessed 16 February 2014). http://www.jointcommission.org/SentinelEvents/SentinelEventAlert/sea_24.htm

[55] Perlis, C.S., Campbell, R.M., Perlis, R.H., Malik, M. and Dufresne, R.G.J. (2006) Incidence of and Risk Factors for Medical Malpractice Lawsuits among Mohs Surgeons. Dermatologic Surgery, 32, 79-83. http://dx.doi.org/10.1097/00042728-200601000-00016

[56] Neily, J., Mills, P.D., Eldridge, N., Dunn, E.J., Samples, C., Turner, J.R., et al. (2009) Incorrect Surgical Procedures within and outside of the Operating Room. Archives of Surgery, 144, 1028-1034. http://dx.doi.org/10.1001/archsurg.2009.126

[57] Al-Rawi, H. and Varma, S. (2012) The Use of a Hand-Held Mirror to Reduce Litigation and Improve Communication in Dermatological Surgery. British Journal of Dermatology, 167, 446-447. http://dx.doi.org/10.1111/j.1365-2133.2012.10866.x

[58] Hussain, W. (2012) Avoiding Wrong Site Surgery: How Language and Technology Can Help. British Journal of Dermatology, 167, 1186. http://dx.doi.org/10.1111/j.1365-2133.2012.11024.x

[59] Ibrahim, S.F. (2014) Wrong-Site Surgery in Dermatology. JAMA Dermatology, 150, 558-559.

[60] Perri, A.J., Chan, C., Uchida, T. and Wagner, R.F. (2008) Patients' Recall of Visible Skin Biopsy Sites. Skin Cancer, 23, 61-67.

[61] DiGiovanni, C.W., Kang, L. and Manuel, J. (2003) Patient Compliance in Avoiding Wrong-Site Surgery. Journal of Bone and Joint Surgery, 85, 815-819.

[62] Campbell, R.M., Perlis, C.S., Malik, M.K. and Dufresne, R.G. (2007) Characteristics of Mohs Practices in the United States: A Recall Survey of ACMS Surgeons. Dermatologic Surgery, 33, 1413-1418. http://dx.doi.org/10.1097/00042728-200712000-00001

[63] Holmkvist, K.A., Rogers, G.S. and Dahl, P.R. (1999) Incidence of Residual Basal Cell Carcinoma in Patients Who Appear Tumor Free after Biopsy. Journal of the American Academy of Dermatology, 41, 600-605.

[64] Rossy, K.M. and Lawrence, N. (2012) Difficulty with Surgical Site Identification: What Role Does It Play in Dermatology? Journal of the American Academy of Dermatology, 67, 257-261. http://dx.doi.org/10.1016/i.jaad.2012.02.034

[65] McGinness, J.L. and Goldstein, G. (2010) The Value of Preoperative Biopsy-Site Photography for Identifying Cutaneous Lesions. Dermatologic Surgery, 36, 194-197. http://dx.doi.org/10.1111/j.1524-4725.2009.01426.x

[66] Ke, M., Moul, D., Camouse, M., Avram, M., et al. (2010) Where Is It? The Utility of Biopsy-Site Photography. Journal of the American Academy of Dermatology, 36, 198-202. http://dx.doi.org/10.1111/j.1524-4725.2009.01425.x

[67] Jawed, S.I., et al. (2014) Dermoscopy to Identify Biopsy Sites Before Mohs Surgery. Dermatologic Surgery, 40, 334-337.

[68] Laumann, A.E. and Derick, A.J. (2006) Tattoos and Body Piercings in the United States: A National Data Set. Journal of the American Academy of Dermatology, 55, 413-421. http://dx.doi.org/10.1016/j.jaad.2006.03.026

[69] Chuang, G.S. and Gilchrest, B.A. (2012) Ultraviolet-Fluorescent Tattoo Location of Cutaneous Biopsy Site. Dermatologic Surgery, 38, 479-483. http://dx.doi.org/10.1111/j.1524-4725.2011.02238.x

[70] Chameleon Body Art Supply. Material Safety Data Sheet for BMX1000-Chameleon Tattoo Ink.

[71] Chuang, G.S. and Gilchrest, B.A. (2012) Ultraviolet-Fluorescent Tattoo Location of Cutaneous Biopsy Site. Dermatologic Surgery, 38, 479-483. http://dx.doi.org/10.1111/j.1524-4725.2011.02238.x

[72] Lemperle, G., Romano, J.J. and Busso, M. (2003) Soft Tissue Augmentation with Artecoll: 10-Year History, Indications, Techniques, and Complications. Dermatologic Surgery, 29, 573-587. http://dx.doi.org/10.1046/j.1524-4725.2003.29140.x

[73] Shah, R.K., Kentala, E., Healy, G.B. and Roberson, D.W. (2004) Classification and Consequences of Errors in Otolaryngology. The Laryngoscope, 114, 1322-1335. http://dx.doi.org/10.1097/00005537-200408000-00003

[74] Shah, R.K., Nussenbaum, B., Kienstra, M., et al. (2010) Wrong-Site Sinus Surgery Inotolaryngology. OtolaryngologyHead and Neck Surgery, 143, 37-41. http://dx.doi.org/10.1016/j.otohns.2010.04.003

[75] Stahel, P.F., Sabel, A.L., Victoroff, M.S., et al. (2010) Wrong-Site and Wrong-Patient Procedures in the Universal Protocol Era: Analysis of a Prospective Data-Base of Physician Self-Reported Occurrences. Archives of Surgery, 145, 978-984. http://dx.doi.org/10.1001/archsurg.2010.185

[76] Knight, N. and Aucar, J. (2010) Use of an Anatomic Marking Form as an Alternative to the Universal Protocol for Preventing Wrong Site, Wrong Procedure and Wrong Person Surgery. The American Journal of Surgery, 200, 803-807; Discussion 807-809. http://dx.doi.org/10.1016/j.amjsurg.2010.06.010 
[77] Haynes, A.B., Weiser, T.G., Berry, W.R., et al. (2009) A Surgical Safety Checklist to Reduce Morbidity and Mortality in a Global Population. The New England Journal of Medicine, 360, 491-499. http://dx.doi.org/10.1056/NEJMsa0810119

[78] De Vries, E.N., Prins, H.A., Crolla, R.M., et al. (2010) Effect of a Comprehensive Surgical Safety System on Patient Outcomes. The New England Journal of Medicine, 363, 1928-1937. http://dx.doi.org/10.1056/NEJMsa0911535

[79] Panesar, S.S., Noble, D.J., Mirza, S.B., et al. (2011) Can the Surgical Checklist Reduce the Risk of Wrong Site Surgery in Orthopaedics? - Can the Checklist Help? Supporting Evidence from Analysis of a National Patient Incident Reporting System. Journal of Orthopaedic Surgery and Research, 6, 18. http://dx.doi.org/10.1186/1749-799x-6-18

[80] Gawande, A. (2009) The Checklist Manifesto. 1st Edition, Metropolitan Books, New York, 79.

[81] Clarke, J.R., Johnston, J., Blanco, M. and Martindell, D.P. (2008) Wrong-Site Surgery: Can We Prevent It? Advances in Surgery, 42, 13-31. http://dx.doi.org/10.1016/j.yasu.2008.03.004

[82] DiGiovanni, C.W., Kang, L. and Manuel, J. (2003) Patient Compliance in Avoiding Wrong-Site Surgery. Journal of Bone and Joint Surgery, 85, 815-819.

[83] Bergal, L.M., Schwarzkopf, R., Walsh, M. and Tejwani, N.C. (2010) Patient Participation in Surgical Site Marking: Can This Be an Additional Tool to Help Avoid Wrong-Site Surgery? Journal of Patient Safety, 6, 221-225. http://dx.doi.org/10.1097/PTS.0b013e3181fd19ec

[84] Knight, N. and Aucar, J. (2010) Use of an Anatomic Marking Form as an Alternative to the Universal Protocol for Preventing Wrong Site, Wrong Procedure and Wrong Person Surgery. The American Journal of Surgery, 200, 803-807; Discussion 807-809. http://dx.doi.org/10.1016/j.amjsurg.2010.06.010

[85] Mahar, P., Wasiak, J., Batty. L., Fowler. S., Cleland, H. and Gruen, R.L. (2012) Interventions for Reducing Wrong-Site Surgery and Invasive Procedures. Cochrane Database of Systematic Reviews, No. 9, Article No. CD009404. http://dx.doi.org/10.1002/14651858.cd009404.pub2

[86] Chang, H.-H., Lee, J.-J., Cheng, S.-J., et al. (2004) Effectiveness of an Educational Program in Reducing the Incidence of Wrong-Site Tooth Extraction. Oral Surgery, Oral Medicine, Oral Pathology, Oral Radiology, and Endodontology, 98, 288-294. http://dx.doi.org/10.1016/j.tripleo.2004.01.018

[87] Dagi, T.F., Berguer, R., Moore, S. and Reines, H.D. (2007) Preventable Errors in the Operating Room-Part 2: Retained Foreign Objects, Sharps Injuries, and Wrong Site Surgery. Current Problems in Surgery, 44, 352-381. http://dx.doi.org/10.1067/i.cpsurg.2007.04.002

[88] Giles, S.J., Rhodes, P., Clements, G., et al. (2006) Experience of Wrong Site Surgery and Surgical Marking Practices among Clinicians in the UK. BMJ Quality and Safety, 15, 363-368. http://dx.doi.org/10.1136/qshc.2006.018333

[89] Liou, T.-N. and Nussenbaum, B. (2014) Wrong Site Surgery in Otolaryngology-Head and Neck Surgery. The Laryngoscope, 124, 104-109. http://dx.doi.org/10.1002/lary.24140

[90] American Academy of Ophthalmology Eliminating Wrong Site Surgery (accessed 30 May 2015). 